\title{
Liquid Chromatography/Tandem Mass Spectrometry
}

National Cancer Institute

\section{Source}

National Cancer Institute. Liquid Chromatography/Tandem Mass Spectrometry. NCI

Thesaurus. Code C122168.

An analytical technique wherein liquid chromatography is coupled to tandem mass

spectrometry in order to separate, identify, and quantify substances in a sample. 